\title{
MARÍA LUISA PUGA, UNA CONCIENCIA DESCENTRALIZADA
}

\author{
ERna Pfeiffer
}

Karl-Franzens-Universitaet Graz

\section{LA MUERTE DE UNA ESCRITORA - UN BALANCE PROVISIONAL}

Cuando un/a escritor/a muere, se produce una súbita ruptura de perspectiva. Un "cambio definitivo" (FS: 244). ${ }^{1} \mathrm{~Pa}-$ radójicamente consiste en que a partir de ese momento ya nada cambiará. Todo se para, todo (nos) separa.

A María Luisa Puga no le gustaría esa perspectiva. A ella, que tanto ahínco solía poner en la descripción de los cambios, de los minúsculos, imperceptibles, sutilísimos cambios; que en su obra eran como un síntoma de vida, de que la vida seguía, esas "[f] ormas continuamente en movimiento" (PP: 281).

Pero ahora es ese cambio exagerado, excesivo, ese punto a partir del cual ya nada será como antes, donde se abre una fisura, una grieta, un vacío que al mismo tiempo puede ser no tanto término sino punto de partida para otro estado físico: "Como si se me hubiera resquebrajado una espesa capa en la que hasta ese momento había estado envuelta” (PP: 150 ss.). María Luisa Puga murió el 25 de diciembre de 2004, día de $\mathrm{Na}$ (ti)vidad, de re-nacimiento.

${ }^{1}$ Voy a marcar con las siguientes siglas las obras de MLP (en orden cronológico): $\mathrm{PO}=$ Las posibilidades del odio (1978), $\mathrm{CAA}=$ Cuando el aire es azul (1980), PP = Pánico o peligro (1983), FS = La forma del silencio (1987), $\mathrm{A}=$ Antonia (1989), $\mathrm{RL}=$ Las razones del lago (1991), LV = La viuda (1994), $\mathrm{LR}=$ La reina $(1995), \mathrm{IV}=$ Inventar ciudades $(1998), \mathrm{NMM}=$ Nueve madrugadas y media (2003), DD = Diario del dolor (2004). 
Es la hora de los críticos (y María Luisa Puga es una de las escritoras mexicanas menos estudiadas: hay muy pocos estudios serios, una sola tesis doctoral, la de Irma López [1996], y tampoco en Internet son abundantes los sitios web dedicados a ella). Llega la hora del balance, nos tocan las preguntas imprescindibles: ¿qué quedará de María Luisa Puga? ¿Cuál es la esencia de su obra? De la obra de una escritora que aborrecía las esencias, las identidades y las perspectivas cerradas: "Eran como México cuando Lourdes lo decía y hablaba de identidad, de lucha de clases, de esencia... era, se me presentaba así ante los ojos, una cosa cerrada y en la que no se podía entrar" (PP: 165).

Quizás ésta sea su “esencia”, su logro mayor, su especialidad: esa conciencia descentralizada, esa mirada oblicua que, según Sigrid Weigel (1988), sería típica de la escritura de la mujer (así, "esencializando", "generalizando" a su vez por género). Este "estar afuera" o "mirar de lado" que se da tantas veces en pasajes inolvidables como éstos:

Era horrible, como si ese mirar por la ventana se me hubiera quedado marcado en la percepción. Me sentía ahí, y lejos, apartada de todo, exactamente igual que si lo mirara todo desde mi ventana (PP: 236).

Me resbalé un poquito para afuera y es como si lo viera todo de la parte de atrás — de arriba o de abajo, da lo mismo—, el caso es que lo vi sin estar adentro (CAA: 63).

Ahora todo era intemperie, afuera, y yo también (PP: 274).

Quería estarme yendo, lejos, lo más lejos posible. Lejos lejos lejos. No quería romper. Quería estar lejos (NMM: 91).

Y este "estar afuera" también se convierte en programa literario, en poética: "Colocarte, digamos, un paso fuera de ti... fuera de todo. Así es como hay que escribir...” (CAA: 27).

2. De OBSESIONES Y DESCENTRALIZACIONES

Ya se nota que este ímpetu de "descentralizarse", de deslizarse hacia los márgenes, de alejarse del foco del poder y situarse en 
la periferia, es casi como una obsesión, tanto en la escritora/ escritura como en la persona de carne y hueso. Que se desplazó a Londres, París, Italia, África, durante diez años para "no vivir en el centro" (NMM: 108). Que después de pasar una etapa en la ciudad de México también se autoexilió de la capital y se mudó al pueblo de Zirahuén, en el estado de Michoacán.

$\mathrm{Al}$ volver a leer, con motivo de la muerte de María Luisa Puga, toda su obra para tener en mente el panorama completo, me he dado cuenta de que desde la primera hasta la última línea están presentes determinados leitmotivs, ciertas constantes, que se someten a variaciones, a modificaciones, pero que no desaparecen. Nunca. Y no son solamente lo que llamaríamos en alemán "Versatzstücke", decoraciones movibles que se llevan de un lugar a otro, que en cualquier momento se pueden usar aquí o allá para ocupar un hueco, no: son motivos recurrentes, verdaderas insistencias, "temas" en el mejor sentido de la palabra. Renacen como tentetieso, no se dejan suprimir, son una presencia constante, casi un tic. Y son pocos: he contado una treintena de los que vuelven y vuelven a aparecer: la forma, el espacio, la escritura, el silencio, el odio, la orfandad, la ciudad, los gestos, el colonialismo, la infancia, el vacío, el tiempo, el cambio, la crisis... Y México. México siempre.

\section{UN INTENTO DE OBJETIVACIÓN}

Para dar una imagen objetiva de esta subjetiva impresión, hice la prueba de hallar motivos recurrentes en dos textos que llevan exactamente veinte años de distancia: Pánico y peligro, la novela del premio Xavier Villaurrutia (1983), y Nueve madrugadas y media, una de las más recientes (2003). Los resultados se pueden apreciar en el siguiente diagrama: 


\section{Diagrama 1}

Puga: Comparación de campos semánticos

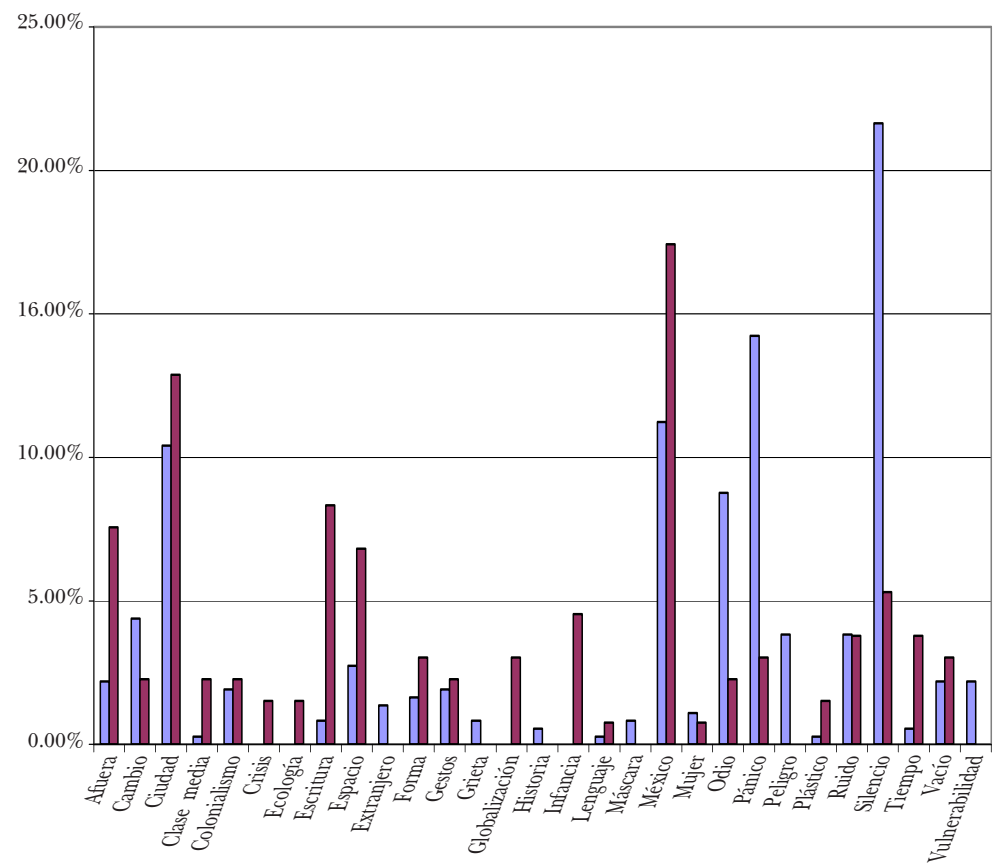

Se puede ver, incluso gráficamente, que hay insistencias evidentes, aunque van apareciendo nuevos temas (la crisis, la ecología, la globalización), mientras que otros desaparecen o se mitigan (el pánico, el silencio, el odio).

Quise hacer un experimento y mostrar el "esqueleto" de las dos novelas, con sólo esta treintena de temas "obsesivos", para ver en qué orden aparecen. El resultado son dos "poemas en prosa”, casi letanías, en el característico estilo nominal de la misma autora. Veamos: 


\title{
Diagrama 2
}

\author{
Pánico y peligro (1983)
}

Cambio. Ciudad. Forma. Silencio. Silencio. Máscara. Tortura. México. Silencio. Ruido. Silencio. Silencio. Pánico. Pánico. Peligro. Silencio. Silencio. Pánico. Peligro. Fragilidad. Traducción. Vulnerabilidad. México. Ciudad. Pánico. Silencio. México. Pánico. México. Pánico. México. Ciudad. Ciudad. Ruido. Silencio. Espacio. Silencio. Silencio. Silencio. Escritura. Silencio. Silencio. Pánico. Colonialismo. Tiempo. Odio. Pánico. Silencio. Odio. Odio. Mujer. Silencio. Silencio. Ciudad. México. Pánico. Silencio. Pánico. Pánico. Pánico. Ciudad. Historia. Recuerdo. Odio. Odio. Pánico. Recuerdo. Ruido. Odio. Cambio. Ciudad. Extranjero. Odio. Pánico. Vulnerabilidad. Odio. Odio. Silencio. Odio. Pánico. Odio. Pánico. Odio. Silencio. Ciudad. Extranjero. México. Extranjero. México. Silencio. Ciudad. Forma. Silencio. México. Plástico. Ciudad. Ruido. Silencio. Odio. México. Ciudad. Pánico. Pánico. Pánico. Ruido. Colonialismo. Historia. Máscara. Odio. Pánico. Silencio. Vacío. Espacio. Forma. Silencio. Espacio. Espacio. Silencio. México. Silencio. Tortura. Grieta. Silencio. Pánico. Silencio. Odio. Silencio. Gestos. Clase media. Silencio. Ciudad. Mujer. Silencio. Silencio. Cambio. Grieta. Silencio. Pánico. Peligro. Ciudad. México. Odio. Ruido. Silencio. Ciudad. México. Silencio. Cambio. Pánico. Silencio. Exilio. Pánico. Peligro. Silencio. México. Ciudad. Ciudad. Grieta. México. Odio. Mujer. Pánico. Silencio. Silencio. Cambio. México. Silencio. Afuera. Ciudad. Silencio. México. Odio. Ciudad. Espacio. Odio. Peligro. Silencio. Afuera. Ciudad. México. Ciudad. Espacio. México. Ruido. Vacío. Silencio. Vulnerabilidad. Ciudad. Odio. Silencio. Vacío. Máscara. Odio. Silencio. Pánico. Ciudad. Cambio. México. México. Pánico. Odio. Pánico. Ciudad. Ruido. Silencio. Afuera. Afuera. Ciudad. Ciudad. México. México. Odio. Odio. Pánico. Pánico. Silencio. Silencio. Silencio. Silencio. Odio. Pánico. Silencio. Vulnerabilidad. Cambio. Silencio. Pánico. Pánico. Silencio. Silencio. Gestos. Vulnerabilidad. Cambio. Silencio. Silencio. Ciudad. Colonialismo. Escritura. Cambio. Ciudad. México. México. México. Ciudad. Peligro. Exilio. Cambio. Ciudad. Pánico. Ciudad. Colonialismo. Colonialismo. Lenguaje. Silencio. México. Peligro. Silencio. Mujer. Afuera. México. Silencio. Forma. Pánico. Tiempo. Silencio. Silencio. Silencio. Silencio. Vacío. México. Odio. Silencio. Peligro. Cambio. Silencio. Ciudad. México. Afuera. Silencio. Espacio. Vacío. Escritura. Silencio. Pánico. Afuera. Gestos. México. Peligro. Silencio. Vulnerabilidad. Silencio. México. Cambio. Odio. Abierto. Silencio. México. Silencio. Vulnerabilidad. Cambio. Cambio. Pánico. Silencio. México. Ciudad. México. Odio. Extranjero. México. Pánico. Vacío. Vulnerabilidad. Odio. Pánico. Pánico. Vacío. Odio. Ruido. Pánico. Ciudad. Fragilidad. Silencio. Vacío. Cerrado. Colonialismo. Odio. Extranjero. México. Pánico. Ciudad. Pánico. Ruido. Ciudad. Cambio. Pánico. Pánico. Peligro. Pánico. Peligro. Ruido. Ruido. Silencio. Espacio. Pánico. Pánico. Pánico. México. México. Afuera. México. México. Silencio. Traducción. Espacio. Forma. Gestos. Espacio. Cambio. Ruido. Silencio. Ciudad. Forma. Gestos. Odio. Pánico. Ruido. Silencio. Silencio. Ciudad. Ciudad. Colonialismo. Gestos. Gestos. Pánico. Peligro. Peligro.

\section{Diagrama 3}

\section{Nueve madrugadas y media (2003)}




\section{De CAPÍtulos y CIFRAS}

Esto parece muy condensado, muy denso. Esquemático, esquelético, matemático. Por un lado concuerda con el frecuente uso de frases sin verbo en María Luisa Puga, puesto que esta autora gustó de explayarse, dejar fluir, ${ }^{2}$ no centrar ni estructurar demasiado sus narrativas. Como ella misma dice, le "sale" una estructura fragmentaria, quiera o no (Pfeiffer, 1992b: 132). A pesar de esto, casi siempre elige una cifra simbólica para la numeración de capítulos; tiene esta obsesión por los números, sus capítulos casi nunca llevan título sino cifras: en Las posibilidades del odio, son seis; en Cuando el aire es azul, diez; en Pánico o peligro doce, en Las razones del lago cuarenta, en Antonia cincuenta, en La reina diez, en Nueve madrugadas y media, obviamente, nueve y media, y en el Diario del dolor cien. Sólo tres de sus novelas, La forma del silencio, La viuda e Inventar ciudades, funcionan de otra manera; no obedecen a esta manía matemática en sistema decimal o duodecimal. La más "descentralizada", pues, parece Nueve madrugadas y media, que lleva su "irregularidad" ya desde el mismo título, autoironizante y tal vez emblemático de la negación a redondear la cifra diez. Escrito casi en vísperas de la muerte de la autora. Como símbolo de lo trunco que quedó su vida, cercenada por el cáncer imprevisto, fulminante.

\section{De ESQUeletos y CAPARAZONES}

Pero quedémonos en las características de la estructura literaria de María Luisa Puga, para emplear una metáfora sacada del reino de los animales, que tanto interés ocuparon en

${ }^{2}$ Cf. el siguiente pasaje que podría hacer las veces de poética oculta: "Estas conversaciones tampoco tienen linderos ni ritmo. Fluyen en los momentos que fluyen y de igual manera se interrumpen" (FS: 141). O también en Antonia: "No necesitaba de frases perfectamente estructuradas y coherentes. Entendía que las cosas eran así: sin terminar; sin definirse" (A: 15). 
la autora hasta el punto de que son dos perros los narradores de Las razones del lago. Mientras que en los vertebrados es la osamenta la que lleva el peso del cuerpo, en los insectos suele ser el caparazón, la superficie. En la obra literaria, esta superficie equivaldría al discours, mientras que el "esqueleto" sería la histoire. Los textos de María Luisa Puga se asemejan a esa complexión de "escarabajo", quizás de inspiración kafkiana-gregor-samsiana (también le gustaría la idea de metamorfosis, supongo).

Algo que llama la atención en la obra de María Luisa Puga es la poca espectacularidad de su estilo. Es una escritura paciente, detallada, enamorada de lo fluido, sin trucos especiales, sin mayores experimentos formales. Siempre mirando de lado, de soslayo, reflejando su propio discurrir, autorreflexivo, metaliterario, anti-ilusionista. El lenguaje mismo, las palabras, la escritura, la lectura, se convierten en temas principales. Escribir como modo de explicarse el mundo. Incluso los nombres de los perros: Novela y Relato (RL), Poeta y Barna (CAA), no dejan de tener su alusión "meta" literaria.

\section{Perspectivas “otras"}

En la obra de María Luisa Puga, la perspectiva narrativa con frecuencia parte desde un enfoque infantil: sea en Cuando el aire es azul, Pánico o peligro, La forma del silencio o en Inventar ciudades, son (al menos parcialmente, en algunos capítulos o párrafos) niños o niñas quienes contemplan con estupor el mundo adulto, poco comprensible, extraño: "No es fácil ser niño" (IC: 61). Niños y jóvenes que muchas veces, además, son huérfanos. ${ }^{3}$ La orfandad como modo extremo de no pertenecer, ni a la familia, ni al país, ni a nada:

[...] lo que importa es cómo se fue abriendo el mundo, revelando, con todos estos cambios. Cómo fui descubriendo acciden-

${ }^{3}$ Incluso el perro que recoge la niña en Inventar ciudades se llama/lo llama ella "Huérfano" (IC: 96). 
talmente cosas que tú no has podido ver porque estás envuelto en una identidad. La gente como yo no la tiene, como tampoco tiene una ciudadanía ni una pertenencia nacional (PP: 197).

Yo por eso quiero el anonimato. No pertenecer a ninguna categoría. Por eso leo, para identificarme con mil personajes, para vivir en épocas distintas, para tener muchas patrias (NMM: 50).

Este mundo visto de abajo, de lado, desde la diferencia, desde la incomprensión, me parece una particularidad muy significativa del mundo ficticio de la Puga. Constituye un "ser y no ser" al mismo tiempo, un estar y no estar, una tercera posición, un in-between, un "third space" (Bhabha, 1994), un vaivén constante que no sólo se da entre niños y adultos, sino también entre hombres y mujeres ("esa cosa voraz y ensimismada, amorfa, que es el ser mujer", FS: 61), ${ }^{4}$ jóvenes y viejos, así como entre representantes de distintas culturas:

Porque eso es lo que pasa cuando leo mis cuadernos: soy yo y no soy yo. Soy un dolorosamente ya no, como cuando me zarandeaba atolondradamente entre Roma y París, de tin-marín, sin saber en dónde tenía que arrancar mi vida verdaderamente, puesto que en México, hasta los veinticuatro, no había sido mi vida lo que tenía que arrancar sino yo arrancarme de la vida de los otros, de todo aquel México [...] (IC: 109).

¿Qué no es ahora el mundo así a causa de la inmigración laboral, política...? Como que nadie está en su sitio. Como que aquello del sitio de origen va perdiendo realidad (FS: 113). ${ }^{5}$

${ }^{4}$ Cf. ese pasaje donde se hace hincapié en dos de estas "fronteras" por donde se desliza la autora: "Qué rara es esa frontera entre la niñez y la adolescencia, y qué distinto la viven hombres y mujeres" (FS: 71). Al final de la novela se vuelve a esa noción de pérdida de solidez, de contornos: "De golpe el mundo es distinto: pierde sus linderos, sus puntos de referencia, sus rincones cobijantes. Uno se siente afuera, extrañamente solitario y lleno de curiosidad" (FS: 241). "Uno", en forma masculina, es sinónimo del "yo" femenino, que se hesita en usar.

${ }^{5}$ Las posibilidades del odio, por supuesto, está lleno de alusiones a las distintas pertenencias o hibridaciones, pero más refiriéndose a casos concretos, no tanto generalizando o abstrayendo ( $c f$. Pfeiffer, 1992a). 
Puga establece una pequeña diferencia entre "extranjero/a" y "fuereño/a"; lo que queda es la sensación de estar fuera de un todo que se percibe homogéneo:

Al llegar a Kenia a uno le sorprendía la franqueza de las miradas. Lo directas y evidentes que eran. Son dos formas de existir y ambas me sorprenden. Me desorientan. Me hacen sentir extranjera...

Eso. Acá me siento fuereña. Es otra cosa (IC: 168).

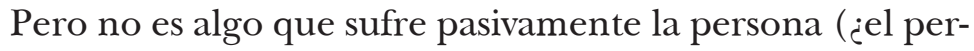
sonaje, la autora?), es algo que se adquiere con toda conciencia: "Queríamos no tener país. Ser de ninguna parte" (A: 12), aunque la consecuencia sí puede ser dolorosa a veces: "Era también una sensación de no tener piso bajo los pies. En Londres estábamos fuera. Ahora estábamos afuera del afuera. Un viaje dentro del viaje" (A: 99).

El displacement, el alejarse del centro geográfico y observar desde la distancia, constituye una característica innegable de María Luisa Puga. Para un observador europeo, implica un descentralizarse doble, ya que invierte las perspectivas "centro-periferia" a escala mundial. El "centro", para ella, es México:

La altiva ciudad de México. El Distrito Federal. El valle de México. La meseta del Anáhuac. Como se quiera, pero el centro del país innegablemente. Y no sólo porque el Ejecutivo esté ahí, o sea, está ahí por ser la punta de la pirámide. Ahí se forja la historia del país, aunque muchos de sus episodios se lleven a cabo en otras partes. Todo acaba por recalar en el Distrito Federal.

Las provincias miran resentidas en esta dirección: también nosotras tenemos nuestra historia, nuestro orgullo. El D.F., no se inmuta (FS: 240).

Es la pug(n)a entre la ciudad y la provincia, entre el D.F. y Acapulco, entre la capital y Zirahuén. Es también la apertura, el dejar entrar lo otro, mezclarse, la hibridación: "Sin embargo, hacer lo que vamos a hacer es precisamente dejar 
entrar lo nuevo, y hay que hacerlo si queremos sobrevivir... ni siquiera es lo nuevo; es lo otro..." (CAA: 257).

Si no, uno se asfixia en un pueblo donde "el aire es azul". En este sentido, la única "pertenencia” sería a "ese grupo amorfo, no grupo, que constituían los fuereños” (IC 26). Es, también, un vaivén entre México y Europa (en Antonia), entre México y África, Kenya en especial (en Las posibilidades del odio). A este respecto, esto dijo la autora en una entrevista que me concedió en Eichstätt (Alemania), en 1989:

[...] el hecho de que yo quería contarle a un público latinoamericano que en África encontré a América Latina, porque ahí vi el subdesarrollo en que había vivido siempre [...], sobre todo viviendo en un lugar como Acapulco que es donde yo pasé mi infancia. Yo creo que los lectores, la gran mayoría lo entendieron cuando leyeron el libro, se entendieron, se dieron cuenta que yo no estaba tratando de mostrarles África (Pfeiffer, 1992b: 125 ss.).

El colmo de la otherness, de la alteridad, lo vemos en el capítulo dos de Las posibilidades del odio, en el que la mirada desde abajo se lleva hasta el extremo, personificada en un mendigo negro, con una pierna amputada:

¿Qué sabía el mendigo de las fuerzas socioeconómicas que pugnaban por hacer de Kenya una nación independiente y moderna; esas fuerzas que se sometían a una lógica de desarrollo mediante la acumulación de capital?

Sabía que, por ejemplo, de la maraña de piernas que poblaban su horizonte, unas eran más lujosas que otras. Unas eran blancas, otras negras. Unas más firmes, otras tambaleantes. De la ciudad sí, lo sabía todo. Por dónde cruzar sin ser atropellado; en dónde detenerse para no ser percibido. Cuáles basureros eran los mejores (PO: 33).

$\mathrm{Al}$ mirar a ese negro mendigo mirando los zapatos desde abajo pasa a diario un niño, un niño negro, que a su vez lo mira —doble perspectiva quebrada, refractada, doble enajenamiento- La autora utiliza entonces el estilo indirecto 
libre, otra manera de descentralizar, de mediar, de enajenar. Encontramos un fenómeno parecido en Las razones del lago, en la que ni siquiera son marginados humanos, outsider, representantes de otras etnias o culturas a los que se les entrega el hilo conductor del relato, sino voces pertenecientes al reino animal: los perros Novela y Relato. Dice la autora sobre el porqué de esta perspectiva insólita, en la entrevista antes mencionada: "Está contada por los perros del pueblo. Entonces el sentimiento de curiosidad me obliga a ver el mundo desde otro ángulo, y la historia se arma una vez que yo ya estoy muy habituada a ser ese ángulo de..., esa perspectiva" (Pfeiffer, 1992b: 128).

Estos perros ven como al margen del todo a una pareja de escritores, que salieron del centro, del D.F.: "Una pareja de mediana edad que, según dijeron, andaban buscando terreno para construirse una casa frente al lago. Les encantaba, dijeron. Querían salirse del D.F. Planeaban venirse a vivir para acá, dijeron, y dedicarse a escribir. [...] Nosotros estábamos echados por ahí, dizque dormidos. Y un día, dijeron, escribiremos sobre usted" (RL: 25).

Unos perros que observan a unos escritores que observan al pueblo para escribir sobre él. Una puesta en abismo bastante compleja. Y cambia el estilo, aun en sus características exteriores: hay más juegos de palabras, más figuras retóricas, algo como un "placer bestial" de hacer visible la superficie del discurso. Frases monovocálicas que podrían asemejarse al ladrido perruno: "Son broncos todos" (RL: 34), "Polvo, polvo, polvo por todos lados" (RL: 95). Frases sin verbos que podrían simbolizar el ritmo de esos ladridos: "Luego silencio. Luego llanto de mujeres. Luego nada" (RL: 34). El silencio, el llanto, la nada, como ejemplos radicales de descentralizarse, de negarse a articular, de salirse del lenguaje humano y, por ende, de la escritura. Un lenguaje que puede ser traicionero: "Hay casi que entrecerrar los ojos; mirar de ladito para encontrarle ese rasgo engañoso al lenguaje. Engañoso. No satisfactorio" (FS: 62). Y otra vez el observador externo: "Miramos desde afuera, desde la invisibilidad" (RL: 
50). Reaparecen los zapatos, la perspectiva "zapatesca”, por no decir zapatista: "La cantidad de zapatos, de piernas, de movimientos delante de nuestras narices" (RL: 110). ${ }^{6} \mathrm{Y}$ la drástica inversión de perspectiva: "En nuestra experiencia es mejor no meterse entre humanos. Son totalmente irracionales" (RL: 124). La radical descentralización.

\section{ESCRIBIENDO EN SEGUNDA PERSONA}

Otra característica formal muy llamativa sería la narración en segunda persona, estrategia predilecta de María Luisa Puga. Un "tú" que a su vez se cuestiona al instante:

Bach, tu cuarto, la ventana desde donde se ven los volcanes... la patrulla que se acerca. El tipo del Malibú que te habla agresivo - con su anillote de oro, olor a vetiver. La maldita lluvia.

¿Y quién es ese tú, ese nosotros y ellos que a cada instante aparecen en el texto? ¿Por qué no contar una historia derecha, sin andarle escabullendo el cuerpo? ¿Qué viste, qué oíste, qué sabes? Tú, tú que eres quien te has arrogado el privilegio de ocupar la atención de los lectores (FS: 102).

Pánico y peligro ya empieza en segunda persona: "Imagínate" (PP: 7). Toda la novela, cosa poco frecuente, está escrita en segunda persona, dirigida a un tú masculino, amante. Pero poco a poco la narradora va quitándole importancia a esa segunda persona, va apropiándose del proceso de escritura, y entonces el "tú" es al mismo tiempo "yo". La destinataria es la protagonista-narradora misma, Susana: "Voy entendiendo lo que pasa. Con los cuadernos, digo. [...] Ya no pienso tanto en que van a ser para ti. Para ti. Hace un buen tiempo que dejé de escribirlos para ti. Son para mí, por mí,

${ }^{6}$ Hay otra escena de mirada a los zapatos en Diario del dolor, desde una posición de "descentralización" extrema, desde la silla de ruedas: "Con fascinación miro piernas que se flexionan con elegancia; zapatos que comen distancias" (DD: 22). 
obviamente, y es muy de vez en cuando que me acuerdo que los vas a leer tú. Sigo queriendo que los leas; sigo pensando que sólo así van a tener un sentido, pero como que me apropié del proceso de escribirlos" (PP: 234).

A veces, toda una novela se estructura en forma de diálogo, como sucede en Nueve madrugadas y media, donde una escritora ya mayor, de nombre María Luisa Puga, conversa en las madrugadas con un joven estudiante, Hernández, que ya apareció al final de Inventar ciudades; parece ser el interlocutor por antonomasia, un ser que carece de género, que se salió de las categorías "hombre" o "mujer":

—¿Quién es Hernández? [...] No tiene cara, no tiene sexo, no tiene época —le explicó al Huérfano, rascándole la barriga$\mathrm{Y}$ sin embargo es a ese apellido al que le tengo que hablar (NMM: 212).

Hernández, volvió a sentir la mujer; esto es Hernández [...] El interlocutor. Pero no es hombre. No es mujer tampoco. Es quien recibe el vivir que llevo, que he llevado dentro, que conversa con el vivir que veo afuera (NMM: 221).

En Pánico o peligro era el amante el destinatario del cuaderno que escribía la protagonista Susana; en La reina es Ana Cecilia Gómez, "La Reina". Otro ejemplo de una segunda persona que va estructurando toda la novela, donde reza el principio: "Calma. Comencemos por el principio. Ana Cecilia Gómez. Veinticinco años. Casada (sí, casada) desde hace dos años, pero el principio no es ése. ¿Cuándo fuiste reina la primera vez? ¿A los seis? ¿Cinco? No te acuerdas. O te acuerdas de que fuiste reina siempre" (LR: 9).

En el último libro publicado en vida de María Luisa Puga, Diario del dolor (2004), incluso se le habla de tú al Dolor, que viene a ser algo como un personaje siniestro, pero compañero al mismo tiempo:

Eso, mi querido Dolor, se llama vacío. Te quedas colgado sin tener en dónde pisar. Te metes en una cabina de teléfono, que se te aparece como paradero en el espacio, y comienzas a mar- 
car números, pero sabes que es un gesto de inutilidad: el eterno sonar del timbre, los no sé, ¿por qué no llama mejor a...? Números y más números. Tonos amables, pero tan distantes e irreales. No hay realidad, alguien te está inventando en un ataque de ocio (DD: 37 ).

Un Dolor, que en el caso de Puga sería el precursor, el emisario de la muerte, última descentralización de la autora, ésta sí definitiva.

\section{Cronotopos SAcudido}

Desde 1985, con motivo del gran terremoto que sacudió a México, se puede observar en la escritura de María Luisa Puga una toma de conciencia de la crisis económica, política, ecológica, que a su vez se anuncia en el aumento de las palabras "crisis", "grieta", "resquebrajar", "vacío", "vulnerabilidad", pero también en las estructuras internas de sus textos. En una configuración cada vez más fragmentaria, en un cronotopos caótico, como estremecido por otro terremoto simbólico. Hay también alusiones directas, como ésta:

Las diez premisas que sostienen esto: libro, narración, plática... no digo novela, ya que es una de las premisas, se cimbran. Un 19 de septiembre de 1985, temprano en la mañana, se ven inesperadamente sacudidas. Esta vez no es una advertencia parcial, sino un hecho general que a todos nos alude y nos hace percatarnos abruptamente de nuestra vulnerabilidad. Ha pegado un terremoto. Ha alterado una cotidianeidad que por caótica que fuera era la única (FS: 131).

La dispersión estructural ya se anunciaba desde Las posibilidades del odio (1978), que precisamente en 1985 vive su segunda edición; algunos lectores se habrán preguntado si en

${ }^{7}$ Cf. el título de la pieza de teatro de Sabina Berman, La grieta (escrita en 1985, estrenada en el Foro de la Conchita en 1996; México, ISSSTE, 1999, en la serie ¿ya leíssste?). 
realidad se trata más bien de una novela o de una serie de cuentos independientes. Lo único que en realidad une a los seis capítulos no son los narradores ni los personajes, ni tampoco los escenarios (hablan seis narradores distintos, actúan seis distintos protagonistas, hombres, mujeres, blancos, negros, en África y en Italia), sino la historia de Kenya. Historia que se recuenta, a manera de crónica, en unas tablas cronológicas, en cursiva, intercaladas entre los capítulos (Edobor, 2006).

En La forma del silencio, que es la primera novela después del terremoto, la narradora se mueve en continuo vaivén entre Acapulco, México, la infancia, la edad adulta, el pasado, el presente. Y en Inventar ciudades nos encontramos con una estructura tripartita, entre Mirada, Tacto y Oído, que dividen cada uno de los capítulos en tres partes con preponderancia de uno de los sentidos. Observando con detalle se notará que dentro de cada apartado el enfoque se desliza de uno a otro personaje: Lorenza, Licha, Carlos —niña, mujer adulta, casi vieja, hombre- Continuamente se perciben estos shifts de punto de vista, casi imperceptibles.

\section{Postrera Descentralización}

Hacia el final de Inventar ciudades se empieza a hablar de la muerte:

— Tenemos que hablar de la muerte — - le dijo un día Licha.

—¿Por qué?

- Carlos y yo somos ya mayores. A nuestra edad uno empieza a pensar en la muerte.

-Pero cualquiera puede morir — protestó Lorenza [...]

Pues sí. La niña le había dado una lección. ¿Para qué adelantarse? Carlos también lo había dicho. ¿Para qué adelantarse? (IC: 210).

Y sí se adelantó María Luisa Puga: murió muy temprano. Apenas 60 años. ¿ ¿Su amor por las cifras redondas? Quiero 
creer que para ella fue otro modo de descentralización, quizás una "última forma del silencio" (FS: 256) que afortunadamente no será tal porque quedan sus textos. Volveremos a encontrarla, en otra forma, ya sin Dolor; a ella, su historia, convertida en escritura, en legado, en lectura: "Una historia que puede contar para verla fuera de sí, para verla en los demás; para darla a los demás" (CAA: 13).

Así no valdrá para ella lo que dicen los perros Novela y Relato en Las razones del lago: "Es horrible el olvido en el que caen los muertos" (RL: 74). Será más bien una transición a otro estado, más inmaterial, incorpóreo, hecho palabra, lenguaje, novela y relato, tal como ella misma lo formulara en La forma del silencio: "Entender de pronto que eso [...] estaba ya vivido. Que uno, sin proponérselo, había abierto una puerta a una vastísima intemperie. Que todos se quedaban de este lado y era uno el que debía trasponerla y comenzar a avanzar hacia allá, no se sabía qué. Daba miedo y era fascinante" (FS: 245).

\section{BibliogRAFÍA}

Textos de María Luisa Puga

Novela:

(1985² [1978]), Las posibilidades del odio, México, Siglo XXI / SEP (Lecturas Mexicanas, Segunda Serie, 15).

(1980), Cuando el aire es azul, México, Siglo XXI (La Creación Literaria).

(1983), Pánico o peligro, México, Siglo XXI (La Creación Literaria). (1987), La forma del silencio, México, Siglo XXI (La Creación Literaria).

(1989), Antonia, México, Grijalbo.

(1991), Las razones del lago, México, Grijalbo.

(1994), La viuda, México, Grijalbo.

(1995), La reina, México, Planeta Mexicana (Biblioteca Breve).

(1998), Inventar ciudades, México, Alfaguara.

(2003), Nueve madrugadas y media, México, Alfaguara. 


\section{Cuento:}

(1979), Inmóvil sol secreto, México, La Máquina de Escribir.

(1981), Accidentes, México, Martín Casillas (Serie La Invención).

(1987), Intentos, México, Grijalbo.

(2001), De intentos y accidentes, México, Instituto de Seguridad y Servicios Sociales de los Trabajadores del Estado.

\section{Ensayo:}

(1980), "Literatura y sociedad", en Revista Mexicana de Ciencias Políticas y Sociales, 102, pp. 103-109.

(1983), La cerámica de Hugo X. Velázquez: cuando rinde el horno, México, Martín Casillas.

(1987), "El lenguaje oculto de la realidad", Tinta, 5, pp. 63-67.

(1990), Ruptura y diversidad, México, Consejo Nacional para la

Cultura y las Artes / unam (Textos de difusión cultural, Serie Diagonal).

(1991), Lo que le pasa al lector, México, Grijalbo (Narrativa Grijalbo). (1991), "El solapado realismo en la novela mexicana", en Karl

Kohut (ed.), Literatura mexicana hoy. Del 68 al ocaso de la revolución, Frankfurt am Main, Vervuert, pp. 167-175.

(1995), Crónicas de una oriunda del kilómetro X en Michoacán, México, Consejo Nacional para la Cultura y las Artes (Cuaderno de viaje).

(2004), Diario del dolor, México, Alfaguara / Universidad del Claustro de Sor Juana/ Consejo Nacional para la Cultura y las Artes.

Literatura infantil:

(1985), El tornado. Cuento, dibujos de Rosario Valderrama, México, CIDCLI (La Hormiga de Oro).

(1991), Los tenis acatarrados, México, ECO.

(1994), La ceremonia de iniciación, México, FCE (Travesías).

(2005), A Lucas todo le sale mal, México, FCE (A la orilla del viento).

Autobiografía:

(1990), De cuerpo entero: el espacio de la escritura, México, unam / Corunda.

En colaboración:

(1989), Signos de identidad. Textos de Carlos Martínez Assad, Guillermo Bonfil Batalla, María Luisa Puga y Carlos Monsi- 
váis; fotógrafos: Raúl E. Díscua, Enrique Hernández Morones, México, UnAM.

(1987), Itinerario de palabras (con Mónica Mansour), México, Folios Ediciones.

\section{Crítica}

Anderson, Danny J. (1990-1991), "Cultural Conversation and Constructions of Reality: Mexican Narrative and Literary Theories after 1968", Siglo XX / 20 th Century, 8, pp. 11-30.

Ballmaier, Priska M. (2001), Von der Möglichkeit, ich zu sagen: Versionen weiblicher Lebensentwürfe im Werk mexikanischer Autorinnen, Hamburg, Kovac (Schriftenreihe Feminat, 10).

Bнавна, Номі K. (1994), The location of culture, Londres, Routledge. Bradu, Fabienne (1987), "Todos los otros, el otro", en Fabienne Bradu, Señas particulares: escritora. Ensayos sobre escritoras mexicanas del siglo xx, México, Fondo de Cultura Económica, pp.118-135.

De Beer, Gabriella (1996), Contemporary Mexican Women Writers: Five Voices, Austin, University of Texas Press, pp. 11-57.

Domenella, Ana Rosa (1996), "Las marcas de la orfandad", en Nora Pasternac, Ana Rosa Domenella y Luzelena Gutiérrez de Velasco (eds.), Escribir la infancia. Narradoras mexicanas contemporáneas, México, El Colegio de México, pp. 147-178.

Edobor, Gudrun (2006), Abgrenzung und Suche nach Identität in "Las posibilidades del odio" von María Luisa Puga (tesina inédita), Universidad de Graz, Austria.

López, Irma M. (1996), Historia, escritura e identidad: la novelística de María Luisa Puga, Nueva York / Vienna [etc.], Lang (Wor(1)ds of change, 23).

Montes Garcés, Elizabeth (1997), "La metáfora de la construcción en Las razones del lago de María Luisa Puga“, Revista de Literatura Mexicana Contemporánea, Universidad de Texas en El Paso, 3, pp. 89-93.

Pellicer, Juan (1997), "La Viuda: una femineidad utópica”, Revista Iberoamericana, 181, LXIII, pp. 689-696.

PfeIFFER, ERna (1990), "Entwicklungspolitische Aspekte im Romanwerk von María Luisa Puga (Mexiko)”, JEP, Journal für Entwicklungspolitik, 6, 1, pp. 59-68.

- (1992a), "Aspectos tercermundistas en Las posibilidades del odio, de María Luisa Puga”, en Juana Alcira Arancibia (ed.), Litera- 
tura del Mundo Hispánico (Actas del VIII Simposio Internacional de Literatura), Quito, Universidad de San Francisco/ Instituto Literario y Cultural Hispánico, pp. 181-187.

Pfeiffer, Erna (1992b), "Lo que me hace empezar una novela es mi curiosidad", en EntreVistas. Diez escritoras mexicanas desde bastidores, Frankfurt am Main, Vervuert Verlag, pp. 123-135. [Edición mexicana: EntreVistas desde bastidores. Diez escritoras mexicanas, México, SERSA, 1993, pp. 123-135].

- (2006), "Textkörper - Körpertexte: Leben mit Behinderung in Werken zeitgenössischer lateinamerikanischer Autorinnen: Alicia Kozameh, Elena Poniatowska, María Luisa Puga”, en Anita Prettenthaler-Ziegerhofer (ed.), Menschen mit Behinderung: Ein Leben wie andere auch?, Graz, Grazer Universitätsverlag, pp. 247-256.

Valdés, María Elena de (1998), The Shattered Mirrors: Representations of Women in Mexican Literature, Austin, University of Texas Press.

Weigel, Sigrid (1988), "Der schielende Blick. Thesen zur Geschichte weiblicher Schreibpraxis", en Inge Stephan y Sigrid Weigel, Die verborgene Frau. Sechs Beiträge zu einer feministischen Literaturwissenschaft, Berlín, Argument-Verlag, pp. 83-137.

Artículos y reseñas en periódicos e Internet

Aguilar Ballardo, Claudia (2004), "De camino a Santa Clara: En busca de María Luisa Puga”, en MiMorelia.com (http://www. mimorelia.com/vernota.php?id=8279, 2007-03-20).

GüEmes, César (2003), "Redita el Fondo de Cultura Económica su novela Pánico o peligro, escrita hace 20 años. Todo lo vivido es susceptible de escribirse, dice María Luisa Puga”, en La Jorna$d a, 28$ de febrero de 2003 (http://www.jornada.unam.mx/ 2003/02/28/02an1cul.php?origen=cultura.html, 2007-03-20).

Luiseldi, Alexandra (1981a), "María Luisa Puga: voy a ser escritora", en El Nacional, 29-7-1981, p. 28.

Luiseldi, Alexandra (1981b), "María Luisa Puga: estoy viendo a México", en El Universal, 30-7-1981, p. 26.

Montaño, Erica / Fabiola Palapa / Arturo Jiménez (2004), "Murió María Luisa Puga a los 60 años; escribir, su máxima pasión", en La Jornada, 26 de diciembre de 2004 (http://www.jornada. unam.mx/2004/dic04/041226/02an1cul.php, 2007-03-20). 
Morales, Patricia (1984), "Reseña de Pánico o peligro", en Sábado, Suplemento de Unomásuno, 14-3-1984, p. 17.

Rodríguez, Héctor Manuel (s.a.), "Desde niña María Luisa Puga mostró en Acapulco sus dotes de narradora, dice su tía Carmen Muñúzuri”, en http://www.suracapulco.com.mx/anterior/2005/enero/05/pag2.htm, 2007-03-20.

Rojas, Carlos (s.a.). "Biografía", en http://www.literaturainba. com/escritores/maluisa_puga.htm, 2007-03-20.

Salinas Salinas, Adela (1991), "Los miedos, las lenguas, los pesares: entrevista a María Luisa Puga", Revista de la Universidad de México, 46, pp. 49-51. 